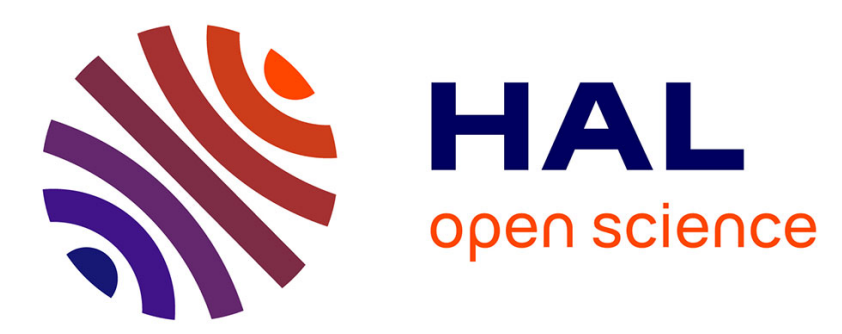

\title{
Aspects matériels du don d'animaux exotiques dans les échanges diplomatiques
}

\author{
Thierry Buquet
}

\section{To cite this version:}

Thierry Buquet. Aspects matériels du don d'animaux exotiques dans les échanges diplomatiques. Bauden, Frédéric. Culture matérielle et contacts diplomatiques entre l'Occident latin, Byzance et l'Orient islamique (XIe-XVIe s.) (Actes du colloque de Liège, 2015), Brill, pp.177-202, 2021, Islamic History and Civilization, 183, 978-90-04-46533-6. hal-02139420

\section{HAL Id: hal-02139420}

\section{https://hal-normandie-univ.archives-ouvertes.fr/hal-02139420}

Submitted on 11 Jun 2021

HAL is a multi-disciplinary open access archive for the deposit and dissemination of scientific research documents, whether they are published or not. The documents may come from teaching and research institutions in France or abroad, or from public or private research centers.
L'archive ouverte pluridisciplinaire HAL, est destinée au dépôt et à la diffusion de documents scientifiques de niveau recherche, publiés ou non, émanant des établissements d'enseignement et de recherche français ou étrangers, des laboratoires publics ou privés. 


\title{
Aspects matériels du don d'animaux exotiques dans les échanges diplomatiques
}

\author{
Thierry Buquet, CNRS (CRAHAM UMR 6273, Université de Caen Normandie) \\ https://www.craham.cnrs.fr/thierry-buquet/ \\ Orcid : 0 ooo-0oo3-2956-8217
}

Ce document est la version postprint de l'article suivant : Buquet, Thierry, «Aspects matériels du don
d'animaux exotiques dans les échanges diplomatiques ", in Culture matérielle et contacts diplomatiques
entre l'Occident médiéval, Byzance et l'Orient islamique (XI'-XVI ${ }^{e}$, éd. Frédéric Bauden, Leiden-Boston: Brill,
2021 (Islamic History and Civilizations 183), 177-202. https://doi.org/10.1163/9789004465381 oog.

Abstract : Les animaux exotiques les plus rares et les plus chers, comme l'éléphant ou la girafe, avaient une place de choix parmi les cadeaux diplomatiques entre Occident latin, monde byzantin et Orient islamique. Mais le don d'un éléphant ou d'une girafe nécessitait une logistique importante, comprenant la capture dans le milieu naturel - fort éloigné des capitales arabes - le transport, les soins vétérinaires, l'alimentation et le logement au départ et à l'arrivée chez le destinataire du cadeau. Les témoignages sur ces réalités matérielles des ménageries médiévales sont très rares et les informations transmises peu précises. Nous essaierons néanmoins, à partir de quelques exemples, d'évaluer les difficultés de cette logistique du cadeau diplomatique, pouvant conduire à la mort des animaux transportés et donc à la «destruction», totale ou partielle, du cadeau diplomatique. Nous évoquerons une autre contrainte importante : la durée nécessaire allant de la capture initiale au don final, pouvant prendre plusieurs mois, voire plusieurs années. Les souverains désireux d'offrir les animaux les plus rares devaient donc être en contact avec des marchands spécialisés capables de fournir et de vendre les espèces les plus éloignées. Nous évoquerons donc, quand la documentation le permet, le coût financier de telles entreprises, notamment le prix d'acquisition de certains animaux. Nous apporterons un contrepoint à l'exotisme zoologique indien ou africain en donnant quelques exemples d'importation d'animaux du Grand Nord, notamment des ours blancs et des gerfauts, ces derniers étant extrêmement prisés des fauconniers arabes. Offrir des animaux aussi rares et chers, venant des régions éloignées du Nord et du Sud, parfois selon la demande même du récipiendaire, nécessitait des réseaux marchands complexes, pour parvenir, en fin de compte à une mise en scène du don.

Mots clés : diplomatie, ménageries, animal exotique, girafe, éléphant, gerfaut, transport, capture

\section{Acquisition}

La présence très régulière d'animaux exotiques parmi les cadeaux offerts lors d'ambassades entre souverains, princes et empereurs est bien connue dans les mondes latin, byzantin et musulman au Moyen Âge et à l'époque ottomane'. Ce type de présent était déjà fréquent dans l'Antiquité ${ }^{2}$. Même s'ils ne constituent pas la majorité des cadeaux, loin de là, les animaux sauvages sont une part importante du don ou du tribut, car ils en constituent la part la plus spectaculaire ${ }^{3}$. Les contacts diplomatiques et commerciaux entretenus par le monde arabo-musulman avec l'Afrique de l'Est et l'Inde permettaient de se procurer relativement facilement des animaux sauvages rares, souvent inconnus en Europe ou au Proche-Orient. Les souverains musulmans ont donc fait un usage intensif de ce type de présent, car ils considéraient par exemple que l'éléphant ${ }^{4}$ et la girafe ${ }^{5}$ étaient

Behrens-Abuseif, Practising diplomacy; Drocourt, Les animaux comme cadeaux d'ambassade ; Delort, Le prince et la bête ; Reindl-Kiel, Dogs, Elephants, Lions.

2 Bodson, Les animaux exotiques.

3 Pour la période mamelouke, Behrens-Abuseif, Practising diplomacy, chapitre 8. J'ai utilisé une version non paginée de cet ouvrage (format epub). Les renvois, par la suite, mentionnent le numéro de chapitre et le numéro d'appel de note le plus proche. Ces numéros sont identiques à ceux du livre imprimé.

4 Voir les remarques sur l'éléphant de Mas'ūdī, Prairies d'or iii, 18-19; VII, 127-9. 
des cadeaux de roi. À titre d'exemple, le tableau suivant montre cette utilisation d'animaux africains lors d'ambassades envoyées par le sultan Baybars au XIII ${ }^{\mathrm{e}}$ siècle, à destination des souverains mongols, d'Espagne, de Sicile, et de Byzance. Avec en bonne place la girafe, mais aussi l'éléphant et le zèbre ${ }^{6}$. [178]

Table 8.1: Animaux offerts par Baybars à plusieurs souverains entre 1261 et 1263

\begin{tabular}{llll}
\hline Année & Animaux & Souverain & Royaume ou empire \\
\hline 1261 & girafe, éléphant, zèbre, etc. & Alfonso X & Espagne \\
1261 & girafe & Michel VIII & Byzance \\
1262 & girafe & Manfred & Sicile \\
1263 & girafes, éléphants, zèbres, singes, etc. & Berke & Horde d'or \\
\hline
\end{tabular}

Au-delà de leur rareté et leur aspect spectaculaire, ces animaux avaient aussi un prix élevé, car il avait fallu les acheter ou les faire capturer, puis les faire acheminer depuis leurs régions d'origine jusqu'au pays du souverain récipiendaire.

Le cadeau de girafes à la fin du Moyen Âge, entre XIII ${ }^{\mathrm{e}}$ et $\mathrm{XV}^{\mathrm{e}}$ siècles, donne un exemple très parlant des difficultés rencontrées pour faire parvenir des animaux rares et exotiques. La carte suivante vous montre le trafic de girafes où l'animal est capturé et exporté d'Afrique subsaharienne, envoyé vers Aden puis le Caire vers l'Europe, le Maghreb, l'Asie centrale ou Byzance? Des girafes ont même été amenées jusqu'en Bengale et en Chine au $\mathrm{Xv}^{\mathrm{e}}$ siècle $^{8}$, avec les grands expéditions de Zheng $\mathrm{He}^{9}$.

Sans aller jusqu'à pouvoir «mesurer » le coût réel de toute la chaîne logistique permettant d'amener une girafe ou un éléphant depuis l'Afrique (en ajoutant l'Inde pour l'éléphant), je vais, dans cet article, présenter une approche de cette chaîne logistique, malgré un relatif manque de précision des sources que j'ai consultées. Si les sources arabes, notamment mameloukes, sont relativement bavardes sur les cadeaux et les animaux, elles ne donnent que trop peu de détails sur les conditions matérielles de capture, de transport et de soins. Quant aux sources narratives latines, elles sont encore plus rares à ce sujet ; néanmoins, ces sources peuvent être complétées par des documents d'archives, notamment comptables, de cours princières, de cités ou de marchands. Le présent article, qui va croiser principalement des sources occidentales et arabes, du XII ${ }^{e}$ au XVI ${ }^{e}$ siècle, ne saurait avoir la prétention de l'exhaustivité. Il s'agit donc d'une première approche, qu'il faudrait compléter par un dépouillement plus systématique des sources narratives et comptables.[179]

5 Kruk, Zarafa; Buquet, La belle captive.

6 Pour les références et les sources relatives à ces différentes ambassades, voir Buquet, Animaux exotiques de Baybars.

7 Une première version de cette carte a été publiée et commentée dans Buquet, La belle captive 72.

8 Church, Giraffe of Bengal ; Liscomb, Chinese Commemorative Art.

9 Duyvendak, The True Dates. 
Figure 8.1: Exportations de girafes et cadeaux diplomatiques ( $\left.\mathrm{XIII}^{\mathrm{e}}-\mathrm{XV}^{\mathrm{e}} \mathrm{s}.\right)$

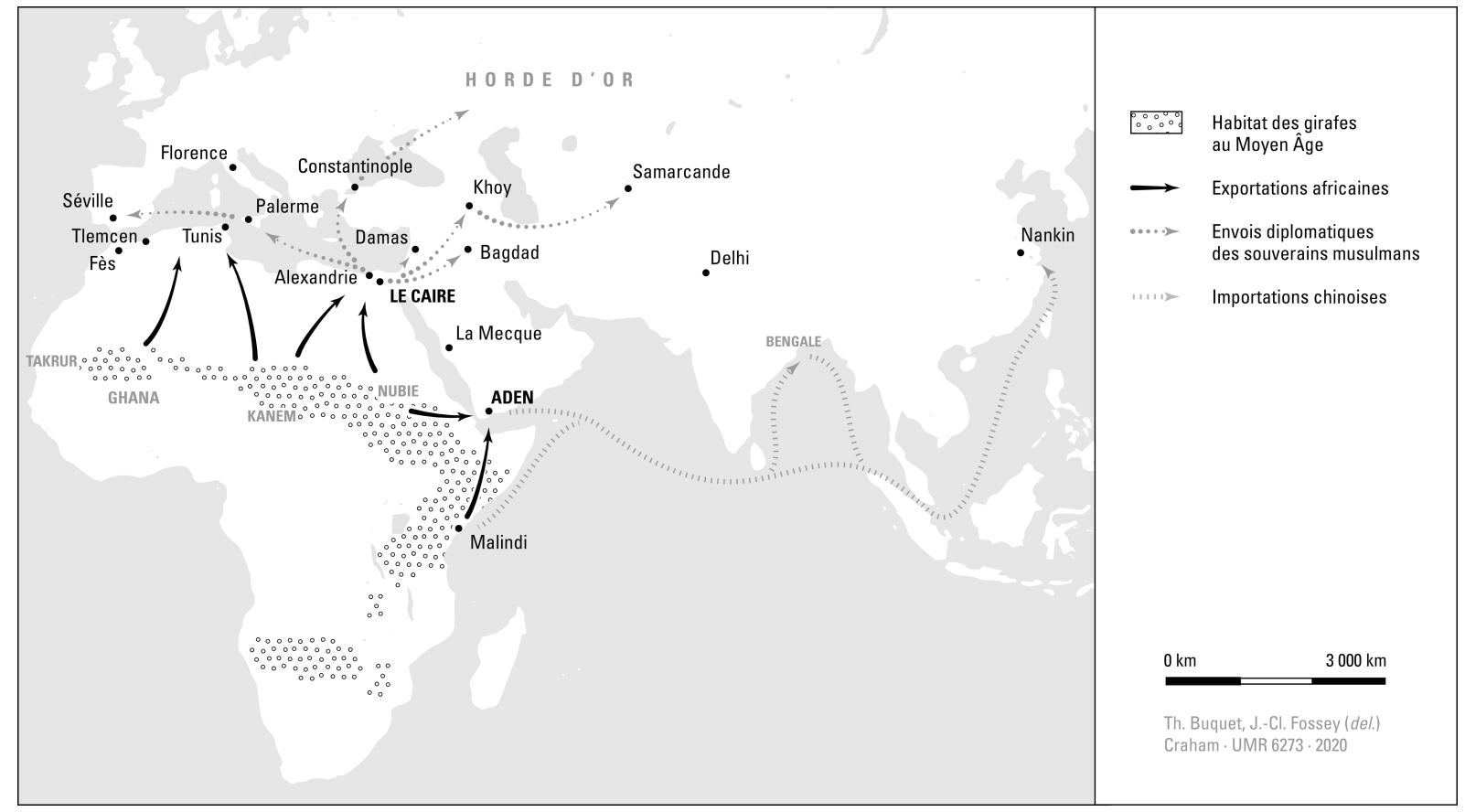

[180]

Dans ce cadre, nous avons choisi d'évoquer plus particulièrement la faune exotique africaine et indienne (éléphant, girafe, lion et autres fauves) et quelques animaux du Grand Nord (ours polaire, faucon gerfaut), la capture et le commerce de ces animaux présentant d'évidentes difficultés logistiques (éloignement des régions de capture, prix élevé, fragilité des animaux). Nous n'évoquerons pas la place centrale du cheval dans l'échange de cadeaux d'ambassade, ni des auxiliaires de chasse plus courants (faucons, autours, chiens) ${ }^{10}$. Il sera donc souvent question de girafes et d'éléphants, mis en scène comme cadeaux royaux ou impériaux, des deux côtés de la Méditerranée ${ }^{11}$. Je donnerai également quelques exemples à propos des lions, vedettes des ménageries médiévales ${ }^{12}$, et qui, par leur présence fréquente dans celles-ci, ont laissé leurs traces dans les sources documentaires occidentales, à propos des coûts induits par leur logement et leur nourriture.

Le plan de cet article va s'organiser en présentant la chaîne logistique de la façon suivante :

- l'acquisition (achat, capture);

- le transport;

- le logement;

- les soins et la nourriture.

10 Sur la place centrale du cheval dans les échanges diplomatiques avec Byzance, voir Drocourt, Les animaux comme cadeaux d'ambassade 74-9.

11 Pour Byzance, voir ibid. 83-5.

12 Je reviendrai plus loin, dans la partie consacrée au logement, sur l'anachronisme de ce mot de ménagerie, que j'utilise malgré tout, faute d'autre terme plus approprié. 


\section{Obtenir les animaux : capture et commerce}

Si les cadeaux matériels pouvaient être facilement fabriqués ou achetés sur place en Orient (citons les textiles, pierres précieuses, parfums et épices, armes, vêtements, livres précieux), la plupart des animaux offerts devaient être importés de parfois très loin, en Afrique ou en $\mathrm{Asie}^{13}$.

Sans rentrer dans le détail pratique des modes de capture, notamment par piégeage, des différentes espèces, il faut néanmoins signaler qu'il était fréquent de capturer les bêtes sauvages en bas âge, afin, d'une part, de faciliter leur transport et d'autre part de les habituer à l'homme (ou même à les apprivoiser). La mention de capture ou de transport d'éléphanteaux et de girafons est parfois évoquée dans les sources. En effet, les petits étaient plus facilement capturés après que les chasseurs eurent tué leurs mères. Léon l'Africain mentionne, dans sa Description de l'Afrique, que c'est le cas des girafes, prises de cette façon [181] peu après leur naissance ${ }^{14}$. Cette information sera reprise chez d'autres auteurs des $\mathrm{XVI}^{\mathrm{e}}$ et $\mathrm{XVII}^{\mathrm{e}}$ siècles, Marmol y Carvajal ${ }^{15}$, André Thevet $^{16}$ et Brémond $^{17}$, et confirmée par Bougainville en 1771 lors de son voyage en Afrique du Sud ${ }^{18}$.

Quelques éléphanteaux ont pu être repérés dans les sources. Selon une chronique latine, Saladin offre à l'empereur byzantin en 1188 un petit éléphant (elephantum parvulum) ${ }^{19}$. En 1479, Ercole d'Este est sur le point d'acquérir un éléphanteau de 32 mois venu d'Égypte auprès d'un marchand vénitien $^{20}$. Ibn Iyās mentionne, pour l'année 1510, l'arrivée d'un éléphanteau âgé d'un an à la cour d'al-Ghawri. ${ }^{21}$ En 1591, les marins de Dieppe offrent au roi de France Henri IV un éléphanteau de cinq ans qu'ils avaient fait venir spécialement de Guinée $e^{22}$.

Il était ainsi plus facile de transporter, nourrir et apprivoiser un animal très jeune, surtout quand on considère la taille, le poids et l'appétit de géants comme la girafe et l'éléphant. Ainsi, les premières girafes vues en France et en Angleterre, arrivées en 1827, offertes par le Pacha d'Égypte aux rois de chacun des deux pays, avaient été capturées petites, arrachées à leur mère dans la province du Sennar en Nubie, puis amenées en Égypte avant de traverser la Méditerranée ${ }^{23}$.

Il y a plusieurs façons pour un sultan arabe d'obtenir des animaux exotiques, comme nous avons pu le voir avec les exemples précédents: par cadeau, par le biais d'un tribut, ou par transaction commerciale.

\section{Obtention par cadeau diplomatique et par le baqt nubien}

Le fait de récupérer un cadeau diplomatique pour le ré-offrir aussitôt est un fait bien attesté. En ce sens, les ménageries princières médiévales pouvaient servir de réserve d'animaux vivants, disponibles le cas échéant pour être offerts à d'autres souverains ${ }^{24}$. [182]

13 Behrens-Abuseif, Practising diplomacy.

14 «Les chasseurs ne le prennent sinon petit aux lieux mêmes où il a été nouvellement faonné », Léon l'Africain, $D e$ l'Afrique ii, 9, 281.

15 Marmol y Carvajal, L'Afrique, I, chap. 23 .

16 Thevet, Cosmographie universelle. Tome premier, ix, 13, 388v.

17 Brémond, Voyages en Égypte 112.

18 Bougainville, Voyage autour du monde 351-2.

19 Brand, The Byzantines and Saladin 171. Source citée: Magnus Presbyterus Reichspergensis Chronica (MGH SS 17, $512)$.

20 Meli, Firenze di fronte al mondo islamico 244. Source citée (269, note 9) : Caleffini, Croniche (1471-1494).

21 Behrens-Abuseif, Practising diplomacy chap. 8, note 52.

22 Colace et Maneuvrier, L'éléphant africain offert à Henri IV par des marins de Dieppe (1591).

23 Lagueux, Geoffroy's Giraffe 231.

24 Sur les ménageries médiévales, voir Buquet, Ménageries arabes; Buquet, Ménageries médiévales; Giese, Tierhaltung; Delort, Le prince et la bête ; Hauck, Tiergarten. Le vieil ouvrage de Loisel, Histoire des ménageries de l'Antiquité à nos jours, peu scientifique, doit être utilisé avec beaucoup de précautions : les sources citées, souvent fautives, doivent être vérifiées de façon systématique. 
Par exemple, le roi de France Louis IX (futur saint Louis) reçut un éléphant du sultan mamelouk Aybak lors de la première croisade du roi en $122^{25}$. Peu après son retour en France, le roi offre l'animal en 1255 à Henri III d'Angleterre; cet animal est resté célèbre par le dessin naturaliste qu'en fit Mathieu Paris ${ }^{26}$. Nūr al-Dīn, émir d'Alep de Damas, nous donne, au XII siècle, un autre exemple frappant de cette redistribution. Il reçoit de Saladin un zèbre et un éléphant; ensuite, puis il fait suivre certains de ces cadeaux à son neveu qui règne sur Mossoul, qui les envoie à son tour au calife de Bagdad $^{27}$ !

Des animaux étaient envoyés régulièrement en Égypte par le souverain rasulide du Yémen, notamment des éléphants, des girafes et des zèbres. Des sources mameloukes signalent que ce type de cadeau arrivait tous les deux-trois ans du Yémen ${ }^{28}$. Il faut noter ici l'importance du port d'Aden pour la collecte, le commerce et l'expédition d'animaux sauvages venus d'Asie ou d'Afrique, comme nous pouvons le voir sur la carte relative aux girafes (figure 5). Les ambassades rasulides, munies de cadeaux, pas seulement animaliers, arrivant à intervalles réguliers, ont pu être considérées par les Mamelouks comme une forme d'allégeance, l'interruption de l'arrivée des présents coutumiers provocant même l'envoi d'une lettre de menace par la calife abbasside en $704^{29}$. L'allégeance est encore plus marquée dans la relation tributaire avec le Nubie chrétienne. Au VII ${ }^{\mathrm{e}}$ siècle, l'Égypte impose un traité de paix, le baqt, qui requiert des Nubiens l'envoi annuel de 360 esclaves, ainsi que d'autres biens comme des animaux rares, girafes et grands félins ${ }^{30}$. Ainsi, les souverains d'Égypte pouvaient ainsi recevoir potentiellement tous les ans deux girafes, pour enrichir la ménagerie du Caire ou être réemployées comme cadeau ${ }^{31}$.

Le tribut nubien et les relations avec les Rasulides permettent donc aux sultans du Caire de réapprovisionner régulièrement leurs ménageries avec des espèces importées d'Afrique de l'Est, afin de remplacer les animaux morts ou ceux partis sous d'autres cieux lors d'importantes ambassades, comme nous l'avons évoqué précédemment pour Baybars au XIII siècle. [183]

\section{Le rôle des marchands}

Dans le cadre d'échanges diplomatiques pouvant être considérés comme une forme d'échange «commercial $»^{3^{2}}$, les cadeaux animaux pouvaient être précisément évalués selon leur valeur marchande. Je n'ai pas trouvé mention de prix pour la girafe ou l'éléphant; par contre d'autres animaux plus fréquemment vendus sur les marchés ont laissé trace de leurs prix dans les sources, comme les gerfauts ou les faucons $\mathrm{s}^{33}$. Si l'on considère ces transactions commerciales et la logistique importante pour faire venir des animaux de très loin, les marchands pouvaient avoir un rôle essentiel dans la livraison de ces présents diplomatiques; ils pouvaient se faire également intermédiaires, comme le mentionne une lettre de Manuel II Paléologue au sultan mamelouk Faraj. Manuel y déclare qu'il a confié cinq faucons et un fauconnier à un marchand de Constantinople $^{34}$. De fait, les marchands européens en mission diplomatique auprès du sultan étaient exonérés de certaines taxes, réservées à l'usage strictement commercial des marchandises,

25 Potin, Saint Louis l'Africain 3 o.

26 Pastoureau, Les animaux célèbres 114-21; Cassidy et Clasby, Matthew Paris.

27 Behrens-Abuseif, Practising diplomacy chap. 7, note 40. Source citée : Ibn Wāṣil.

28 Behrens-Abuseif, Practising diplomacy chap. 3 note 14. Sources citées : Khazrajī et Yamāni.

29 Vallet, Ambassades 275 et 287.

30 Fauvelle-Aymar, Rhinocéros d'or 45-52 ; Spaulding, Reconsideration ; Halm, Der nubische baqt ; Løkkegaard, Baḳt ; Beshir, Nubian Fatimid Relations.

31 Buquet, Ménageries arabes.

32 Vallet, Ambassades.

33 Shehada, From the Far North to the Near East, 371-4.

34 Cutler, Gift exchange 266. Cutler donne d'autres exemples de ce rôle d'ambassadeur confié à un marchand. 
comme l'a souligné Anthony Cutler, évoquant Le livre de l'impôt foncier d'Abū Yūsuf (IX siècle $)^{35}$. Ce juriste précise que les autres objets suspectés de commerce pour le propre compte de l'envoyé seront soumis à l'impôt du dixième. Si le juriste se doit de préciser tout cela, c'est sans doute parce que certains marchands ont pu espérer profiter de cette «immunité » diplomatique pour faire passer leurs autres marchandises, nettes d'impôt...

Il n'était pas rare que considérations politiques et commerciales puissent avoir une égale importance. Par exemple, en 1366, Venise autorise la dépense de 6oo ducats d'or pour envoyer quelques faucons gerfauts à l'émir Yalbughā, à sa demande, pour « qu'il se montre favorable et bien disposé envers nos marchands», dans une lettre envoyée au représentant de Venise à Chypre ${ }^{36}$. Dans ce cas, certains animaux pouvaient être «commandés» par un souverain à ses correspondants.

Les marchands pouvaient faire preuve d'un zèle particulier pour satisfaire leur souverain, afin d'en retirer un bénéfice personnel à court ou à long terme. C'est le cas en 1480 de la ligue hanséate de Bruges qui va mobiliser tout son réseau en mer du Nord et en Baltique (Lübeck, Gdansk, Tallinn, Tartu) pour réunir et faire parvenir au roi de France, à sa demande, un ensemble d'animaux [184] rares, pour en tirer quelque avantage commercial et diplomatique. Lübeck va même vouloir prendre en charge les frais considérables de cette affaire, alors que le roi de France avait offert de payer lui-même ${ }^{37}$. Je reviendrai plus loin sur cette affaire lorsque il s'agira d'évoquer le transport de la faune arctique et subarctique.

Les souverains pouvaient donc s'appuyer sur tout un réseau commercial, au nord de l'Europe, autour de la Méditerranée, ou aux confins du Yémen et de l'Afrique, pour acquérir des animaux rares. En 1239, l'empereur Frédéric II Hohenstaufen obtient des chevaux et des guépards (leopardus) par la vente de denrées alimentaires en Barbarie (probablement la Tunisie avec laquelle il avait établi d'importantes relations commerciales $)^{38}$. Dans les années 1470, René d'Anjou achète des animaux à des marchands venus de Tunis ou de Barbarie (gazelles, autruches, singes et chevaux $)^{39}$. Le 24 mai 1560 , un contrat devant notaire de vente d'animaux exotiques entre des marchands marseillais et deux marchands de Constantine et d'Alger mentionne l'envoi de lions, léopards, et chats sauvages, d'autruches, de moutons à queue large, des singes et de 400 tortues, tous destinés à la ménagerie royale du Louvre à Paris ${ }^{40}$.

\section{Transport}

Comme nous venons de le voir, les marchands et leurs réseaux pouvaient être mobilisés pour assurer le transport des animaux. Par exemple, en 1309, le souverain d'Égypte envoie par bateau à Tunis une girafe, qui voyagea sur le vaisseau d'un marchand ${ }^{41}$. Les cadeaux diplomatiques pouvaient suivre la voie maritime : en 1306, le Yémen envoie en Égypte une importante cargaison de présents (objets et matières précieuses, épices, parfums, tissus, accompagnés chevaux, de plusieurs éléphants, girafes et zèbres (himar 'attābī), le tout expédié sur deux grand navires ${ }^{42}$.

35 Ibid; Abū Yūsuf, Le livre de l'impôt foncier 291.

36 Shehada, Mamluks and Animals 69 ; Mas-Latrie, Histoire de l'île de Chypre ii, 285.

37 Paravicini, Animaux 111-5 et 118.

38 Kantorowicz, CEuvres (L'Empereur Frédéric II) 269 ; Huillard-Bréholles, Historia diplomatica Friderici Secundi V/1, 525 .

39 Arnaud d'Agnel, Comptes du roi René ii, 365 et 372-3.

40 Hamy, Ménagerie des Valois.

41 Zarkashī, Chronique des Almohades 83.

42 Vallet, Ambassades 287-8. 
L'éléphant que Louis IX offre à Henri III en 1254 doit traverser la Manche depuis Wissant, près de Calais, vers Douvres, puis vers Londres par bateau. Mais cette traversée est à la charge des Anglais : c'est le Sheriff du Kent qui est [185] missionné par le roi d'Angleterre pour trouver un navire et un équipage. Les comptes royaux (Close \& Liberate Rolls) ont enregistré les dépenses relatives à ce transport exceptionnel ${ }^{43}$.

Le transport des animaux exotiques a toujours été une étape délicate, entraînant des pertes importantes. Il n'était pas rare que la moitié des animaux étaient morts à l'arrivée - des chiffres semblables sont mentionnés pour les esclaves (6o rescapés pour 300 morts lors d'une ambassade envoyée par le Yémen en $\left.{ }^{1352}\right)^{44}$. À titre d'exemple, citons, pour le Xvi siècle, cette remarque d'André Thevet, dans sa Cosmographie universelle, à propos de six girafes emmenées par des « Turcs » depuis des îles d'Inde :

« Les Turcs donc se saisirent de ces bestes (...), et par force et à coups de bastonnades les mirent en leurs vaisseaux. Mais soit que le changement d'air leur nuisist, ou soit que la soif les accablast, sur le navire, deux y moururent, et deux autres, ainsi qu'ils eurent mis pied à terre au port d'Aden, en Arabie; et les deux du reste furent menées au grand Caire, lesquelles j'ai vues durant le temps de trois mois que je fus en ce lieu, et contemplai à mon aise $e^{45}$.»

Ici c'est donc seulement un animal sur trois qui arrive sain et sauf ! Déjà, en 991, une girafe avait été offerte avec d'autres animaux africains à Manșūr b. Abū 'Āmir par le souverain de Tunis Zīrī b. 'Ațiyya, mais l'animal serait mort pendant le voyage ${ }^{46}$. En 1512, Qānșawh al-Ghawrī reçoit deux éléphants offerts par un roi d'Inde; deux autres sont morts pendant le voyage. Un des deux survivants sera aussitôt envoyé à Istanbul ${ }^{47}$. Ce problème devait être fréquent, car il était d'usage que le coût des animaux morts devait être partagé entre le vendeur et l'acheteur. Par exemple, en 1479, René d'Anjou paie la somme de 8 ducats pour deux gazelles à un marchand venu de Barbarie : une des deux bêtes est pourtant morte durant le voyage ${ }^{48}$.

Nous savons par ailleurs que les sultans mamluks payaient la moitié du prix pour des gerfauts arrivés morts pendant leur long voyage depuis l'Europe, comme l'explique al-Nuwayrī au XIV ${ }^{\mathrm{e}}$ siècle : [186]

«Les marchands ont l'habitude de les ramener des pays étrangers, et si des oiseaux meurent avant d'arriver, ils s'arrangent pour ramener leur plumage aux rois, et ceux-ci leur paient chaque oiseau mort la moitié du prix, ceci pour les encourager à les ramener et les transporter en terre d'Égypte ${ }^{49}$.»

Cette information est donnée au siècle précédent par le géographe Ibn Sacìd, qui signale que les faucons blancs du Nord sont payés à leur livraison 1000 dinars ${ }^{50}$, et 500 quand ils sont morts ${ }^{51}$. Il faut ajouter à cette évocation des gerfauts le coût particulier de leur transport, qui devaient voyager depuis le Groenland ou l'Islande: plusieurs voyages par mer et par terre étaient

43 Cassidy et Clasby, Matthew Paris.

44 Vallet, Ambassades 293. Source citée : Maqrīzī, Kitāb al-Sulūk.

45 Thevet, Cosmographie universelle ix, §131, 388v-389.

46 Morales Muñiz, Fauna éxotica 262-3.

47 Reindl-Kiel, Dogs, Elephants, Lions 279.

48 Arnaud d'Agnel, Comptes du roi René ii, 372-3.

49 Al-Nuwayrī, Nihāyat x, 205.

$5^{\circ}$ Ibn Manglī, De la chasse 133. Ibn Manglī confirme que le prix d'un gerfaut va de 500 à 1000 dinars.

51 Eisenstein, Drei nordeuropäischen Tieren 58. 
nécessaires, il fallait soigner et nourrir (avec de la viande) ces oiseaux fragiles. Tout cela représentait des frais considérables ${ }^{52}$.

Il existe, pour le XIII ${ }^{\mathrm{e}}$ siècle, plusieurs mentions de cadeaux d'ours blancs, offerts à Henri III d'Angleterre et à l'empereur Frédéric II, probablement par le roi de Norvège. La chaîne logistique est ici particulièrement longue et dangereuse : d'abord capturer un ours blanc vivant au Groenland (ceci étant le fait des colonies norroises du Groenland, $d u \mathrm{IX}^{\mathrm{e}} \mathrm{au} X \mathrm{XV}^{\mathrm{e}} \mathrm{s}$.), puis le transporter par bateau jusqu'en Norvège via l'Islande, puis ensuite en Angleterre, et même jusqu'en Italie à la cour impériale ${ }^{53}$. L'animal est imposant et est relativement gourmand, notamment en graisse animale (phoque ou poisson). Plus étonnant encore, les sources arabes nous apprennent qu'un de ces ours polaires fut offert par Frédéric II au sultan de Damas en 630/1233-1334 ${ }^{54}$. Ibn Saīd, contemporain des faits, ne détaille pas les conditions d'arrivée de ce cadeau diplomatique; il a peut-être pu observer l'animal ou obtenir des informations de première main, car il explique que cet ours est originaire des régions les plus septentrionales de l'Europe, qu'il se nourrit de poissons en nageant dans la mer. Il mentionne également la douceur des peaux de cet ours, qui sont également apportées comme cadeaux en Égypte ${ }^{55}$.

J'ai déjà évoqué plus haut que le roi de France Louis XI fait venir autour de 1480, en plusieurs livraisons, un ensemble d'animaux du Nord: il s'agit [187] notamment d'élans, de rennes, d'hermines, de zibelines et d'autres animaux de couleur blanche (belettes et lièvres). Le roi et la ligue marchande hanséate y dépensent des sommes folles. Mais la lenteur des communications et la difficulté de faire venir les animaux depuis notamment les pays baltes et la Scandinavie va aboutir à l'échec de la seconde opération, commencée au printemps 1483. En effet, le roi de France meurt fin août 1483, avant que les hanséates n'aient pu réunir cette ménagerie nordique ${ }^{56}$.

D'autres périls guettaient ces transports: l'attaque des caravanes et la piraterie en mer. Anthony Cutler cite l'exemple suivant: un bateau vénitien emportant des cadeaux envoyés par Saladin en 1192 à l'empereur byzantin Isaac II est capturé par des pirates. Le cadeau comprenait notamment des chevaux, des mulets et des auxiliaires de chasse (animalia ad venationem pertinentia $)^{57}$.

D'autres dépenses devaient être engagées dans le cadre du transport: cages et autre matériel de captivité, nourriture, soins et frais de gardiennage. L'ambassade de Geoffroy de Langley en 1291 auprès de l'Ilkhan de Perse à Tabriz, envoyée par le roi d'Angleterre, a laissé des comptes détaillés. Ceux-ci nous apprennent que l'ambassade, à l'aller, emportait en présent des gerfauts ; à son retour elle a dû ramener en Angleterre un guépard offert par le souverain perse. À l'aller, trois fauconniers faisaient partie de l'ambassade pour s'occuper des gerfauts. À l'étape de Trébizonde, deux autres fauconniers sont engagés avant d'arriver à Tabriz. Outre les salaires des fauconniers, les comptes donnent le détail des frais de nourrissage des oiseaux, à qui l'on donne des poulets (les comptes n'en donnent pas le nombre exact). Il a fallu faire d'autres menues dépenses : de la soie pour les chaperons des gerfauts, peut-être abîmés pendant le transport. Une brève mention de paiement d'un argenteur ne précise pas de quel travail il s'agit (réparation de chaînes ou de boucles ?). Le transport du guépard a occasionné d'autres dépenses. Il fallut d'abord lui fabriquer une cage en bois à Tabriz ; celle-ci dû être réparée ou reconstruite à l'étape de Constantinople sur le chemin du

52 Shehada, From the Far North to the Near East.

53 Vassilieva-Codognet, Blanchart l'ours blanc; Oleson, Polar Bears.

54 Vassilieva-Codognet, Blanchart l'ours blanc ; al-Nuwayrī, Nihāyat XIX, 202 ; al-'Aynī, Iqd al-Jumān 196.

55 Eisenstein, Drei nordeuropäischen Tieren 6 o.

56 Paravicini, Animaux.

57 Cutler, Gift exchange 267 . 
retour. Durant ce séjour, on achète 3 poulets, 3 moutons vivants et la moitié d'un pour satisfaire l'appétit du félin ${ }^{5}$.

À son arrivée, l'animal pouvait parfois subir des quarantaines: ainsi, l'éléphant de Charlemagne est gardé un hiver en Italie, à Vercelli, à partir de son arrivée en octobre 8o1, avant de ne rejoindre Aix-la Chapelle que l'été suivant, le 20 juillet 802 , parce qu'il ne pouvait franchir les Alpes couvertes de neige, selon le témoignage d'Éginhard ${ }^{59}$. Un autre éléphant vit son départ repoussé [188] en 1438, un spécimen que le sultan Barsbāy devait envoyer à Murad II. Barsbāy décédé, c'est son successeur Jaqmaq qui envoie le cadeau, mais il fait patienter Murād en arguant des difficultés dues aux rigueurs de l'hiver, et lui promet que l'animal sera envoyé par bateau en Turquie au printemps ${ }^{6 \circ}$.

Une quarantaine forcée a été causée, non par des questions climatiques, mais par des considérations diplomatiques. Il s'agit, en 1263, d'une ambassade destinée par Baybars à Berke, khan de la Horde d'or, envoyée dans un grand bateau, selon le témoignage détaillé de la Sirat alMalik al-Zāhir ${ }^{61}$. Mais l'ambassade envoyée par Baybars est bloquée par l'empereur Michel VIII, empêchant son passage vers la Mer noire. En effet, Michel ne veut pas froisser les représentants de Hülagü (fondateur de la dynastie mongole des Ilkhanides et ennemi de Berke) présents à sa cour. L'ambassade - et donc le bateau contenant les cadeaux - fut obligée de rester plus de trois ans sur place! Dans cet intervalle, comme nous le racontent Ibn 'Abd al-Z̄āhir (al-Rawḍ al zuăhir) ${ }^{62}$, alFaḍa'il ${ }^{63}$ et al-Nuwayri ${ }^{-64}$, les esclaves et les animaux restés sans soin sur le grand bateau affrété par Baybars périrent presque tous, et les présents se détériorèrent. Berke, posant des questions sur les éléphants et les girafes ${ }^{65}$, se plaindra auprès d'un envoyé de Baybars de la non-arrivée des $\operatorname{cadeaux}^{66}$. Nous ne disposons malheureusement pas à notre connaissance d'autres documents aussi précis relatant les conditions de transport et d'arrivée des éléphants et girafes offerts à Byzance aux XI et XIII siècles. En 1053, l'empereur Constantin IX Monomachos reçoit une girafe et un éléphant envoyés par le sultan d’Égypte. Si Michel Attaleiatès et Michel Psellos ont décrit ces animaux (Psellos utilise notamment l'éléphant pour faire le panégyrique de l'empereur), il ne disent rien des conditions de transport ni de l'hébergement des animaux. De même, Michel VIII reçoit du sultan Baybars une girafe en 1261, qui est très bien décrite par Georges Pachymères, mais là encore sans aucun détail pratique sur son arrivée $e^{67}$. [189]

\section{Logement}

Les souverains de haut rang possèdent souvent une ménagerie susceptible d'accueillir de tels hôtes. J'utilise ici «ménagerie », qui est un terme moderne, anachronique pour les périodes plus anciennes, pour désigner les lieux de captivité des animaux princiers, car il n'existe pas de terme univoque pour décrire cette notion à l'époque médiévale, ni en Orient ni en Occident. De plus, les lieux de captivité ne sont pas la plupart du temps uniques et centralisés comme à l'époque moderne. Les animaux pouvaient être gardés en plusieurs endroits du château, ou dans plusieurs

\footnotetext{
58 Paviot, Séjour de l'ambassade 48-51.

59 Éginhard, Annales, 51-2.

6o Muhanna, Ottoman Mamluk Gift Exchange 192.

61 Sadeque, Baybars 188-9o.

62 Sublet et Miquel, Baybars 94-7.

63 Ibn Abī al-Faḍā’il, Histoire 453-5.

64 Al-Nuwayrī, Nihāyat xxx, 88.

65 Ibn al-Faḍāil, Histoire 461.

66 Sublet et Miquel, Baybars 98.

67 Ševčenko, Wild animals, 77-8.
} 
résidences, dans des espaces spécifiques à leur usage : volières d'apparat, cages de fauconniers, chenils, enclos de bêtes sauvages, parcs à cerfs ou à gazelles, etc. ${ }^{68}$ Les lions et autres fauves pouvaient être gardés dans des fossés aux abords du château, comme au palais du calife à Cordoue $^{69}$. Les lions pouvaient aussi être isolés dans une maison spéciale, comme à Gand au Xv siècle (voir plus loin), ou dans l'« Hôtel des lions » près du Louvre à Paris au XIv ${ }^{\mathrm{e}}$ siècle. À l'entrée de la Tour de Londres, une tour spéciale gardait les lions. À Constantinople, les lions de l'empereur étaient gardés à proximité du palais de Blachernai. Certaines sources latines de la fin du XII siècle laissent supposer qu'il pourrait s'agir d'une tour adjacente au palais ${ }^{70}$.

Ces ménageries permettaient aussi de loger des cadeaux aussi encombrants qu'un éléphant ou une girafe, événement relativement fréquent dans le monde arabo-musulman. C'est le cas du sultan d'Égypte, qui gardait ses girafes à la Citadelle du Caire du XIII ${ }^{\mathrm{e}}$ au XV ${ }^{\mathrm{e}}$ siècle $^{71}$. Mas ${ }^{\mathrm{u}} \mathrm{u} d \overline{\mathrm{l}}$ mentionne que le calife al-Mansūr gardait au VIII ${ }^{\mathrm{e}}$ siècle des éléphants dans ses écuries à Bagdad ${ }^{72}$. Malheureusement, nous ne disposons pas de descriptions des ménageries du Caire et de Bagdad, à une exception près. Al-Maqrīzī nous a transmis la seule présentation détaillée d'une ménagerie pour le monde musulman, elle concerne celle du prince tulunide Khumārawayh, à la fin du IX siècle. Située dans le quartier d'al-Qațā’ic' au nord de Fustat, elle comprenait différentes écuries pour les chevaux, mulets et dromadaires, ainsi que des «maisons » différentes pour les guépards, panthères, éléphants et girafes. Les lions étaient gardés dans le château même du prince, où il avait fait faire une «maison des lions» $(d \bar{a} r a l-s i b \bar{a})$. Cette maison des lions contenait plusieurs chambres voûtées, chacune contenant un lion et sa lionne ; chaque chambre débouchait sur [19o] une salle plus grande. Les gardiens pouvaient isoler chaque salle notamment pour y apporter de la nourriture ou pour nettoyer les cellules. Une trappe, mue par un mécanisme, permettait de faire sortir le lion, puis le gardien rentrait dans la cellule par une autre trappe dans le plafond. La pièce centrale servait aussi d'espace où les lions pouvaient se promener dans la journée. Un personnel spécialisé ( $s \bar{a}$ is pour les lions) était assigné à cette tâche et avait un traitement annuel, des provisions de vivres considérables et des biens abondants ${ }^{73}$.

Dans d'autres villes dépourvues de ménagerie bien établie, il fallait parfois trouver des abris provisoires. En 1340, la chronique d'Ibn Qāọī Shuhba nous apprend qu'un éléphant et une girafe arrivent à Damas. Ils sont en transit: venus d'Égypte, ils sont destinés au prince de Mārdīn. L'éléphant est logé près des écuries du sultan (iștablal-sulțān), la girafe au Khān al-Zāhir. La source ne dit pas combien dura cette étape, mais la foule pu aller voir les animaux et on profita de l'occasion pour faire parader l'éléphant dans la ville aux portes des notables de la cité, suscitant ainsi l'émerveillement ${ }^{74}$.

À Constantinople, juste après la conquête ottomane, des ménageries avaient été établies dans les églises chrétiennes de Saint-Jean du Dihippion et du Christ-Sauveur de Chalke. Ces édifices présentaient une grande hauteur, et on pouvait y placer des espèces différentes dans chacune des chapelles. Plusieurs voyageurs occidentaux aux $\mathrm{XV}^{\mathrm{e}}$ et $\mathrm{XVI}^{\mathrm{e}}$ siècle ont pu visiter ces ménageries, notamment le Arslân Hâne (en turc : «hôtel des lions ») ${ }^{75}$. Ils pouvaient y voir non seulement des lions, mais aussi des girafes, éléphants, camélidés, léopards, lynx, loups, ours, tigres, etc. Mais

68 Buquet, Ménageries médiévales, 99-103.

69 Ševčenko, Wild animals, 8o note 53, citant la Chronique d'Ibn Ḥayyan.

70 Ševčenko, Wild animals, 8 o.

71 Buquet, Ménageries arabes; id, Animalia extranea.

72 Al-Mas'ū $\overline{\mathrm{d}}$, Prairies d'or iii, 18.

73 Al-Maqrīzī, Description de l'Égypte iii, 218-22.

74 Ibn Qāạī Šuhba, Tarīkh i, 132. Je remercie Mathieu Eychenne pour m’avoir signalé ce document.

75 Mikhail, The Animal in Ottoman Egypt 112-3, 124-7 ; Asutay-Effenberger et Effenberger, Zur Kirche. 
éléphants et hippopotames pouvaient être gardés dans d'autres palais, les églises mentionnées n'ayant pas les seuls lieux de captivité des animaux dans la ville ${ }^{76}$.

En Occident latin médiéval, les souverains entretenaient des ménageries depuis au moins l'époque carolingienne ${ }^{77}$. Mais très peu de descriptions ont été conservées, et de façon peu détaillée. Les espaces de captivité étaient situés à l'intérieur ou à proximité des châteaux, parfois dans les fossés. La ménagerie d'Azzo Visconti, décrite par Galvano Fiamma (XIV ${ }^{\mathrm{e}}$ siècle), présente une immense volière (cavea) grillagée de métal, peuplée d'oiseaux chanteurs. Non loin, d'autres cages (cavea) enferment des lions, des ours, des singes, des [191] babouins, des autruches et bien d'autres espèces. Mais le texte en dit bien peu sur l'organisation de l'espace ; il est difficile de savoir si le mot «cavea » désigne effectivement une cage, ou un enclos, une enceinte, voire une cavité creusée dans le sol. La description ne donne pas une idée d'ensemble de la structure et de l'organisation de ce bâtiment, qui est désignée comme une «cavea magna sicut unum pallatium » (enclos grand comme un palais) au pied d'une grande tour du château ${ }^{78}$.

Les animaux les plus fréquemment gardés étaient les lions, les camélidés, les «léopards » (leopardus pouvant désigner jusqu'au XVII ${ }^{\mathrm{e}}$ siècle soit le guépard, soit la panthère $)^{79}$, les singes, les ours et les autruches ${ }^{80}$. L'aménagement des bâtiments construits pour les lions et les autres félins est relativement bien connu pour la fin du Moyen Âge, car occasionnant des travaux réguliers de réparation (barreaux descellés, murs détériorés, etc.), d'aménagement (trappes, fenêtres, lucarnes, ouvertures sur cour) ou d'agrandissement, notamment pour héberger de nouveaux pensionnaires $^{8_{1}}$. À Gand, la rénovation des lieux de captivité vient d'abord réparer le délabrement causé par les animaux : les épais lambris de chêne qui recouvrent les murs sont griffés et détachés par les lions; il faut refaire les barreaux de bois et les grillages mis à mal par les fauves et les remplacer par de solides barres de fer. En 1475, on réaménage les lieux pour créer une clôture de bois pour séparer les lions qui se battent ${ }^{82}$. En 1480, à la cour des ducs de Lorraine, les chambres de lions sont aussi recouvertes de lambris, elles ont des fenêtres munies de barreaux et elles débouchent sur une cour ${ }^{83}$.

Il était beaucoup plus rare de recevoir des éléphants et des girafes en Europe, et il fallait donc parfois improviser. Par exemple, Henri III d'Angleterre fit construire un logement pour l'éléphant qu'il reçut de Louis IX. Cette construction faisait 40 pieds de long sur 20 de large, soir environ $10 \mathrm{~m}$ par 5 ; les comptes royaux (Pipe rolls) de 1255 gardent la trace des dépenses occasionnées ${ }^{84}$. Lorsque la girafe offerte à Laurent de Médicis par le sultan d'Égypte Qā’itbāy [192] arrive à Florence en 1487, elle est logée dans les étables appartenant au pape à Florence. Comme l'hiver approche, son étable est garnie de grands tas de fumier, et on entretient un grand feu pour la réchauffer ${ }^{85}$.

76 Tinguely, L'écriture du Levant 135.

77 Hauck, Tiergarten im Pfalzbereich.

78 Flamma, De rebus gestis ab Azone 16-7.

79 Buquet, Guépard médiéval.

8 o Id., Ménageries médiévales 103-4.

81 Lecoy de La Marche, Extraits des comptes du roi René §106, 35 et §128, 39. En 1455, on agrandit à Angers les logements pour y accueillir des lions arrivant de Florence. La construction et l'aménagement des maisons des lions et « léopards » de Florence est bien documenté pour la fin du XIII ${ }^{\mathrm{e}}$ siècle : König-Lein, Simile alla natura, 87, qui cite des comptes de la République de Florence.

82 Lievois et Van den Abeele, La cour des lions à Gand.

83 Boyé, Animaux d'Afrique 238.

84 Cassidy et Clasby, Matthew Paris.

85 Buquet, La belle captive 83-4. 


\section{Soigner et nourrir}

Il fallait aussi soigner et nourrir les animaux. Comme ceux-ci venaient de loin et étaient assez rares, il pouvait être difficile d'avoir à leur sujet des connaissances vétérinaires suffisantes. La solution fut d'accompagner les animaux de gardiens spécialisés, faisant eux-mêmes partie du cadeau d'ambassade. Au XIV ${ }^{\mathrm{e}}$ siècle, le traité vétérinaire du souverain yéménite al-Malik alMujāhid, le confirme dans un chapitre consacré aux éléphants :

«Les gardiens d'éléphants venus d'Inde et leurs descendants vivant parmi nous au Yémen ont le savoir sur leurs maladies et connaissent les façons de les traiter ${ }^{86} »$.

Vers 930-931, le calife de Cordoue reçoit en cadeau de nombreux animaux : lions, chevaux, gazelles et chameaux. Ces derniers sont accompagnés par un esclave noir expert dans le soin des chameaux $^{87}$. Il en était de même pour les faucons: les gerfauts arrivent accompagnés de fauconniers experts, comme, par exemple, ceux envoyés par un marchant vénitien à la cour de Qalāwūn en $1317^{88}$. Dans son traité de fauconnerie, l'empereur Frédéric II Hohenstaufen signale les soins particuliers à apporter aux gerfauts, consécutifs aux mauvais traitements subis et à la mauvaise nourriture donnée pendant leur long voyage depuis le Nord. Frédéric préconise de laisser au repos ces oiseaux récemment arrivés pendant une saison entière avant de les remettre à la chasse ${ }^{89}$.

Nourrir l'animal ne demandait pas forcément d'expertise (à l'exception de la fauconnerie, dont l'art de l'affaitage est extrêmement codifié et bien connu par divers traités médiévaux), mais pouvait coûter très cher. Pétrarque l'avait remarqué, dans son ouvrage Remèdes aux deux fortunes, se moquant de la vanité des hommes riches et puissants à vouloir posséder des animaux exotiques. [193] Pour lui, l'éléphant ne peut qu'être une folie ruineuse, réservée aux rois, car il remplit une maison entière mais vide les greniers (domum impleat, horreum exhauriat $)^{90}$. À titre d'exemple, l'entretien de l'éléphant de Henri III coutait près de 25 livres par an (1255-1256), une somme considérable pour l'époque ${ }^{91}$. Toujours à la cour d'Henri III, on laisse l'ours blanc pêcher le poisson dans la Tamise ; les comptes ont gardé trace de paiements pour son collier et la longue corde pour le tenir pendant sa pêche ! On fit fabriquer une muselière et une chaîne de fer quand l'animal était hors de l'eau ${ }^{92}$. Ces frais devaient être payés par la ville de Londres (et donc par le contribuable), comme les frais d'entretien de l'éléphant. Il n'était d'ailleurs pas rare que les souverains levassent des impôts particuliers pour nourrir leurs animaux exotiques. À la fin du XII siècle, Baudouin de Hainaut, comte de Flandre, décide d'abolir un vieil impôt qui servait à payer le gardiennage et la nourriture de ses ours, taxe injuste selon lui car prélevée à la fois sur les pauvres et sur les riches ${ }^{93}$. À Barcelone, aux XIV et $\mathrm{XV}^{\mathrm{e}}$ siècles, les lions étaient nourris grâce à un impôt prélevé sur la mosquée et sur la population juive de la ville. Quand, en 1391, les juifs sont dépossédés de leurs biens et ne peuvent donc plus payer cette taxe, le roi Joan crée l'année suivante un nouvel impôt sur les honoraires des hauts fonctionnaires de la ville pour nourrir les fauves. Le montant de cet impôt sera augmenté en 1399 par le roi Marti pour couvrir en plus le salaire du gardien des lions ${ }^{94}$.

86 Shehada, Mamluks and Animals 96.

87 Ibn Hayyan, Crónica del Califa 'Abdarrahman III, cité par Ševčenko, Wild animals, 77, note 34.

88 Shehada, Mamluks and Animals 202, note 115.

89 Frédéric II Hohenstaufen, L'art de chasser 333.

90 Pétrarque, Remèdes 288-9.

91 Cassidy et Clasby, Matthew Paris 3.

92 Calendar of the Liberate rolls iv, 84.

93 Le Glay, Histoire des comtes de Flandre i, 425-6.

94 Adroer i Tassis, Animals exòtics 11-13. 
Le nourrissage des grands félins est bien documenté dans les comptes de la fin du Moyen Âge occidental. Des paiements aux bouchers attestent les commandes importantes journalières pour satisfaire l'appétit des lions. En 1298, le boucher Robertus est payé par la cour du roi Philippe le Bel pour livraison d'un mouton et demi par jour (2,5 en 1305), pour la viande donnée aux lions et aux «léopards ». Le total se monte en 1305 à 572 moutons (somme totale de $140 \mathrm{l}$.), pour 128 jours ${ }^{95}$. Entre $145^{\circ}$ et 1463, à la cour du roi René à Angers, les lions recevaient quotidiennement un demi mouton et les léopards un quart. Ainsi, le boucher Babin vend entre 500 et 600 moutons dans l'année à la ménagerie de René ! Ce total atteint même 800 têtes en 1475 par le boucher Yvain ${ }^{96}$. À la cour de Gand, on atteint 821 moutons par an pour nourrir les lions dans les [194] années 144097. Toujours à Gand, une bergerie et un enclos pour les moutons sont aménagés à proximité de la cour aux lions ${ }^{98}$, et une pièce spéciale pour conserver la viande est attenante à la maison aux lions ${ }^{99}$. À la cour de Lorraine vers 1480, on avait de même installé, à côté des cages aux fauves, une pièce où le gardien stockait et débitait la viande ${ }^{100}$. Ainsi, les fauves disposaient à domicile d'un gardemanger...

La mortalité était très élevée parmi les fauves et l'espérance de vie était souvent réduite à 2 ou 3 ans en captivité, comme par exemple à la ménagerie de René d'Anjou dans les années $1470^{101}$, à la ménagerie des ducs de Lorraine à la même époque ${ }^{102}$. En 1380, à Barcelone, le roi s'inquiète et veut connaître les causes de la mortalité excessive de ses lions, s'ils sont morts de faim ou à cause de mauvais soins, craignant qu'ils n'aient été mal nourris; il prend aussi conseil à propos du régime des lions gardés au palais d'Aljaferia de Saragosse ${ }^{103}$. À la cour de Philippe le Bon, duc de Bourgogne, la garde et le soin de quatre lions sont confiés en 1425 à un boucher, Jacques de Melle, dans la ville de Gand. Il accepte la charge parce qu'on le convainc qu'il pourra tirer profit de l'argent que les «bonnes gens y donneraient à aller voir » les lions. Au bout d'une semaine, Jacques de Melle laisse mourir de faim les lions et demande qu'on augmente la rente journalière de 24 à 30 gros, car il lui semble impossible de les nourrir sans perte avec une somme inférieure. Le boucher obtient gain de cause, mais à 28 gros seulement ${ }^{104}$. Quelques mois plus tard, un jeune lion supplémentaire arrive à Gand et le duc octroie à Jacques de Melle 6 gros supplémentaires par jour pour un demi mouton qu'il donnera quotidiennement à l'animal ${ }^{105}$. Les exemples espagnol et bourguignon montrent à quel point les frais de nourrissage des lions étaient importants, âprement négociés, et sans doute souvent sous évalués pour réduire une dépense qu'on devait juger trop excessive : il faut rappeler que des troupeaux entiers sont engloutis annuellement par les fauves, dans les ménageries évoquées dans cette partie : près de 6oo moutons en quatre mois à la cour de Philippe le Bel, entre 500 et 800 par an à la cour de René d'Anjou et plus de 900 par an, selon mes calculs, à Gand, en 1425. [195]

Pour compenser la mortalité, il y avait régulièrement des naissances en captivité. Citons, pour le XIV ${ }^{e}$ siècle, les lionceaux de Florence (sept mentions entre 1333 et 1384, avec des portées de deux

95 Maillard et Fawtier, Comptes royaux, $\mathrm{n}^{\circ} 4457,217$.

96 Lecoy de La Marche, Extraits des comptes du roi René 30, 35-40 et 44.

97 Ibid., La cour des lions à Gand 85 .

98 Ibid., La cour des lions à Gand 94, 96, 98.

99 Ibid., La cour des lions à Gand 82.

100 Boyé, Animaux d'Afrique 238.

101 Lecoy de La Marche, Extraits des comptes du roi René 44.

102 Boyé, Animaux d'Afrique 239.

103 Adroer i Tassis, Animals exòtics 12.

104 Laborde, Ducs de Bourgogne Preuves I, 216-8.

105 Ibid, 221-2. 
à quatre petits) ${ }^{106}$ et de Venise ${ }^{107}$, ceux de Gand au XV $\mathrm{e}^{\mathrm{e}}$ siècle ${ }^{108}$, ou encore ceux de Nancy en 1483 et $1484^{109}$. Quelques sources arabes mentionnent des naissances de girafons à la citadelle du Caire au $\mathrm{XIII}^{\mathrm{e}}$ siècle ${ }^{\mathrm{IIO}}$ et des témoignages de pèlerins européens décrivent des petits troupeaux en captivité, comprenant mâles, femelles et girafons ${ }^{\text {III. }}$ En évoquant la reproduction des animaux, je ne m'éloigne pas trop du sujet cet article: l'entretien de tels troupeaux, avec des naissances en captivité, permettait au souverain de posséder ainsi une réserve d'animaux frais, d'une part pour remplacer ceux qui mourraient trop rapidement et d'autre part pour offrir facilement ces animaux en cadeau, sans voir à les faire venir de trop loin. Une gestion de stock pour raccourcir la chaîne logistique, en quelque sorte...

\section{Conclusions}

\section{Évolutions et tendances}

L'histoire sur la longue durée des aspects matériels du don d'animaux ne permet pas de discerner des évolutions majeures à l'époque médiévale. Avant le XIII ${ }^{\mathrm{e}}$ siècle en Occident, les sources, tant archivistiques que littéraires, sont hélas très rares sur les cadeaux animaliers. Mais depuis au moins l'époque carolingienne, il existe en Europe des ménageries princières destinées en partie à garder les animaux venus d'Orient. Au-delà du relatif silence des sources, force est de constater que certaines périodes ont vu des échanges diplomatiques plus intenses de part de d'autre de la Méditerranée, concernant des souverains qui ont marqué leur époque, que l'on songe à l'éléphant de Charlemagne, l'éléphant et la girafe de Frédéric II, les animaux envoyés par Baybars, etc. La variété des espèces échangées est assez peu significative dans le temps : éléphants et lions sont offerts à toute époque, considérés comme des animaux royaux par excellence ${ }^{112}$. Mais certaines modes vont avoir une influence : la chasse au gerfaut, prisée par les Mamelouks à partir du XIII siècle, va susciter [196] l'envoi de ces animaux depuis le Grand Nord. L'utilisation du guépard de chasse, très prisée en Italie et en France à la fin du Moyen Âge, va aussi provoquer l'envoi d'un tel cadeau. Ces modes peuvent aussi s'atténuer, voire disparaître : peu à peu le guépard n'apparait plus en Occident, son utilisation à la chasse décline en Europe à partir de la seconde moitié du XVI siècle et cesse alors d'être un présent diplomatique ${ }^{113}$. La girafe n'est plus revue en Europe entre la fin du XV $V^{e}$ et le début du XIX siècle, pour des raisons peut-être liées au déclin de la ménagerie du Caire au détriment de celle de la Constantinople ottomane ${ }^{114}$. Le goût européen change également à la Renaissance : on s'intéresse dorénavant à la faune du Nouveau Monde (perroquets, singes) mais aussi à celle de l'Inde, dans le sillage des voyages portugais : citons le rhinocéros indien et le tigre, ces deux animaux n'ayant été pas revu en Europe au Moyen Âge. Au XVI siècle, les éléphants indiens sont plus fréquents, alors que ceux envoyés par les souverains musulmans de la période médiévale étaient africains ${ }^{115}$.

106 König-Lein, Simile alla natura 88-9. Sources : chroniques de Giovanni et Matteo Villani.

107 Schnoor, Die Löwengeburt 1316.

108 Lievois et Van den Abeele, La cour des lions à Gand 98, 100 et 106.

109 Boyé, Animaux d'Afrique 239.

110 Al-Nuwayrī, Nihāyat ix, 317 ; Maqrīz̄ì, Histoire 106.

111 Buquet, Animalia extranea 26.

112 Buquet, Les animaux exotiques.

113 Buquet, Hunting with Cheetahs.

114 Buquet, Les ménageries arabes et ottomanes.

115 Le célèbre éléphant Hanno, offert par le roi du Portugal Manuel au pape Léon X en 1514 est de l'espèce indienne, d'après le dessin réalisé par Raphaël, cf. Bedini, The Pope's Elephant. L'éléphant de Henri III, donné par le roi de France, est, d'après le dessin qu'en a fait Mathieu Paris, indubitablement de l'espèce africaine. 
Pour le transport et le logement des animaux, les sources sont trop rares et trop peu précises pour discerner une quelconque évolution, temporelle et géographique. Pour les soins apportés aux animaux, on dispose de plus d'informations dans le monde musulman. La littérature vétérinaire arabe est plus prolixe, et certains animaux exotiques, plus fréquemment importés, sont mieux connus qu'en Occident.

\section{Coûts engendrés par les cadeaux animaliers}

Cet article, comme mentionné en introduction, ne fait qu'aborder les questions économiques et logistiques du don d'animaux entre puissants. Une étude de plus grande ampleur, analysant plus systématiquement les sources comptables, permettrait d'établir une estimation des coûts de telles opérations logistiques relatives au transport, à la nourriture, aux soins et à l'hébergement des animaux accueillis dans les ménageries. On y verrait sans doute que cette logistique coûtait bien plus cher que le prix des animaux eux-mêmes. À ce propos, je souhaite citer ici une remarque Doris Behrens Abusaif, dans son récent ouvrage sur les cadeaux à l'époque mamelouk : [197]

«The value of the animals lay not only in their exotic or rare nature, but also in the material value of bringing them to the recipient. ${ }^{116}$ »

Suraiya Faroqhi fait les mêmes remarques concernant la période ottomane : la difficulté et les dépenses nécessaires pour apporter un animal sauvage à Istanbul pouvaient être considérées ellesmêmes comme une source de prestige ; cela signifiait également que le souverain ottoman avait des vassaux dans les contrées les plus éloignées, auxquels il pouvait commander ou se faire offrir ce type de présent ${ }^{117}$.

Si acheminer de tels présents pouvait coûter cher à l'expéditeur, les recevoir pouvait aussi s'avérer ruineux pour le récipiendaire, notamment à cause des frais d'entretien élevés après leur arrivée. Autant les pierres précieuses, tissus, épices et parfums pouvaient avoir une valeur économique directe, et donc enrichir le trésor royal, posséder des animaux aussi rares s'avérait donc être une charge très élevée pour les finances du prince, comme nous l'avons vu avec les dépenses de nourrissage des lions. En plus du plaisir «esthétique» procuré par les animaux, auxquels le prince pouvait être personnellement attaché (lions ou guépards dormant parfois dans les appartements royaux ${ }^{118}$, le souverain pouvait en tirer deux valeurs ajoutées :

- les réutiliser comme cadeau pour un autre souverain ;

- les utiliser comme objets de magnificence et de prestige, pour montrer son pouvoir, étaler ses richesses et montrer par l'exotisme des bêtes toute son influence sur des régions lointaines.

La propagande et la communication ont, de tout temps, exigé des dépenses élevées, mais les coûts en étaient partagés par l'expéditeur et le récipiendaire, par la multitude des échanges, des transferts et du recyclage de ces animaux « diplomatiques ». Si leur entretien était une vraie charge pour le trésor, ces animaux participaient pleinement à la gloire du prince, en tant que signes vivants des relations extérieures et du prestige qu'entretenait le souverain au-delà des mers. [197]

116 Behrens-Abuseif, Practising diplomacy chap. 8, note 63.

117 Faroqhi, Exotic animals 87.

118 Delort, Le prince et la bête 193-5. 


\section{Bibliographie}

\section{Sources arabes}

Abū Yūsuf, Le livre de l'impôt foncier (Kitāb al-Kharāj), trad. E. Fagnan, Paris 1921.

al-'Aynī, 'Iqd al-Jumān fì ta'rīkh ahl al-zamān (extraits), in Ch. Barbier de Meynard (éd.), Recueil des historiens des croisades. Historiens orientaux, t. II, ${ }^{\text {re }}$ partie, Paris 1887, 183-254.

Ibn Abī al-Faḍāàil, Histoire des sultans mamlouks, trad. E. Blochet, Paris 1919, reprint Turnhout 1982.

Ibn Manglī, De la chasse : Commerce des grands de ce monde avec les bêtes sauvages des déserts sans onde, trad. F. Viré, Paris 1984.

Ibn Qāḍī Shuhba, Tarīkh, éd. 'A. Darwīsh, vol. 1-2, Damas 1994.

al-Maqrīzī, Description historique et topographique de l'Égypte (Livre des admonitions et de l'observation pour l'histoire des quartiers et des monuments) $3^{e}-4^{e}$ parties, vol. 3 , trad. P. Casanova, Le Caire 1906.

—__, Histoire des sultans mamlouks de l'Égypte, éd. É. Quatremère, 2 vol., Paris 1837-1845.

al-Mas'ūdī, Les prairies d'or (Murūj al-dahab wa ma‘ādin al-jawhar), trad. C. Barbier de Meynard et A. Pavet de Courteille, 9 vol., Paris 1861-1877.

al-Nuwayrī, Nihāyat al-arab fífunūn al-adab, 33 vol, Le Caire 1929-1998.

Sadeque, S. F. (trad.), Baybars I of Egypt (al-Rawḍ al-zähir fi sīrat al-Malik al-Zāhir), London 1956.

Sublet, J. et A. Miquel (trad.), Les trois vies du sultan Baybars, Paris 1992.

Al-Zarkashī, Chronique des Almohades \& des Hafçides, éd. E. Fagnan, Constantine 1895.

\section{Sources latines et européennes}

Arnaud d'Agnel, G. (éd.), Les comptes du roi René publiés d'après les originaux inédits conservés aux Archives des Bouches-du-Rhône, 3 vol, Paris 19o8-1910.

Bougainville, L. A. de, Voyage autour du monde, éd. M. Bideaux et S. Faessel, Paris 2001.

Brémond, G., Voyages en Égypte, éd. G. Sanguin, Le Caire 1974.

Calendar of the liberate rolls preserved in the Public record office. Vol. IV. 1251-126o, London 1959. http://name.umdl.umich.edu/abh6499.0004.001 (consulté le 15 février 2016).

Éginhard, Annales d'Eginhard et Vie de Charlemagne, éd. F. Guizot, Paris 1824. Texte latin édité dans Annales Regni Francorum, MGH. Scriptores Rerum Germinacarum 6, Hanovre 1895.

Flamma, Galvano de la, Opusculum De rebus gestis ab Azone, Luchino et Johanne Vicecomitibus ab Anno MCCCXVIII usque ab annum MCCCXLII, éd. C. Castiglioni, Bologne 1938.

Frédéric II Hohenstaufen, L'art de chasser avec les oiseaux : le traité de fauconnerie «De arte venandi cum avibus », éd A. Paulus et B. Van Den Abeele, Nogent-le-Roi 200o. [199]

Huillard-Bréholles, J.-L.-A., Historia diplomatica Friderici Secundi, 12 vol., Paris 1852-1861.

Lecoy de La Marche, A., Extraits des comptes et mémoriaux du Roi René, Paris 1873.

Léon l'Africain. De l'Afrique, trad. J. Temporal, 2 vol., Paris 1556.

Maillard, F., et R. Fawtier, Comptes royaux (1285-1314), 2 vol., Paris 1953-1954.

Marmol y Carvajal, L, L'Afrique, trad. N. Perrot d'Ablancourt, I, Paris 1667.

Pétrarque, François. Les remèdes aux deux fortunes, éd. C. Carraud, Grenoble 2002.

Thevet, A., Cosmographie universelle. Tome premier, Paris 1575 .

\section{Références}

Adroer i Tassis, A. M., Animals exòtics als palaus reials de Barcelona, in Medievalia 8 (1988), 9-22.

Asutay-Effenberger, N. et A. Effenberger, Zur Kirche auf einem Kupferstich von Ğugas Inciciyan und zum Standort de Chalke-Kirche, in Byzantinische Zeitschrift 97/1 (2004), 51-94. 
Bedini, S., The pope's elephant: an elephant's journey from deep India to the heart of Rome, Nashville 1998.

Behrens-Abuseif, D., Practising Diplomacy in the Mamluk Sultanate. Gifts and Material Culture in the Medieval Islamic World, Londres et New-York 2014.

Beshir, B. I., New Light on Nubian Fatimid Relations, in Arabica 22/1 (1975), 15-24.

Bodson, L. (éd.), Les animaux exotiques dans les relations internationales: espèces, fonctions, significations. Journée d'étude, Université de Liège, 22 mars 1997, Liège 1998.

Boyé, P., Animaux d'Afrique à la cour des ducs de Lorraine au $\mathrm{XV}^{\mathrm{e}}$ et $\mathrm{XVI}^{\mathrm{e}}$ siècles, in Bulletin philologique et historique du Comite des Travaux Historiques et Scientifiques (1905), 235-44.

Brand, C. M., The Byzantines and Saladin, 1185-1192 : Opponents of the Third Crusade, in Speculum 37/2 (1962), 167-81.

Buquet, T., Animalia extranea et stupenda ad videndum. Describing and Naming Exotic Beasts in Cairo Sultan's Menagerie, in M. A. Walker Vadillo, F. de Asís García García, et M. V. Chico Picaza (éd.), Animals and the Otherness in the Middle Ages. Perspectives across disciplines, Oxford 2013, 25-34. [200] https://hal.archives-ouvertes.fr/halshs-00845246

- La belle captive. La girafe dans les ménageries princières au Moyen Âge, in C. Beck et F. Guizard (éd.), La bête captive au Moyen Âge et à l'époque moderne, Amiens 2012, 65-9o. https://hal.archives-ouvertes.fr/halshs-00664537

- Le guépard médiéval, ou comment reconnaître un animal sans nom, in Reinardus 23 (2011), 12-47. https://hal.archives-ouvertes.fr/halshs-0o655131

- - Hunting with Cheetahs at European Courts: From the Origins to the End of a Fashion, in M. Hengerer et N. Weber (éd.), Animals and Courts (Europe, c. 1200-1800), Berlin 2020, 17-42. https://hal.archives-ouvertes.fr/hal-o2139428

- Les animaux exotiques dans les ménageries médiévales, in J. Toussaint (dir.) Fabuleuses histoires des bêtes et des hommes, Namur 2013, 97-121. https://hal.archivesouvertes.fr/halshs-oogo5429

- Les ménageries arabes et ottomanes, in SSMOCI (Société Suisse Moyen Orient et Civilisation Islamique) Bulletin 38 (2014), 16-9. https://hal.archives-ouvertes.fr/halshs-01070008

- Nommer les animaux exotiques de Baybars, d'Orient en Occident, in C. Müller et M. Roiland-Rouabah (éd.), Les non-dits du nom. Onomastique et documents en terres d'Islam. Mélanges offerts à Jacqueline Sublet, Beyrouth 2013, 375-402. DOI: 10.400o/books.ifpo. 5728

Cassidy, R. et M. Clasby, Matthew Paris and Henry III's Elephant, in Henry III Fine rolls Project Website, Londres 2012, http://www.finerollshenry3.org.uk/redist/pdf/fm-o6-2012.pdf (consulté le 15 février 2016).

Church, S., The Giraffe of Bengal: A Medieval Encounter in Ming China, in The Medieval History Journal 7/1 (2004), 1-37.

Colace, M.-P. et C. Maneuvrier, L'éléphant africain offert à Henri IV par des marins de Dieppe (1591), in Annales de Normandie 68, ${ }^{\circ} 2$ (2018), 61-76. DOI: 10.3917/annor.682.0061

Cutler, A., Gifts and Gift Exchange as Aspects of the Byzantine, Arab, and Related Economies, in Dumbarton Oaks papers 55 (2001), 248-78.

Delort, R., Le prince et la bête, in J. Paviot et J. Verger (éd.), Guerre, pouvoir et noblesse au Moyen Âge. Mélanges en l'honneur de Philippe Contamine, Paris 2000, 185-95.

Drocourt, N., Les animaux comme cadeaux d'ambassade entre Byzance et ses voisins $\left(\mathrm{VII}^{\mathrm{e}}-\mathrm{XII}{ }^{\mathrm{e}}\right.$ siècles), in B. Doumerc et C. Picard (éd.), Byzance et ses périphéries (Monde grec, balkanique et musulman). Hommage à Alain Ducellier (Méridiennes), Toulouse 2004, 67-93. 
Duyvendak, J. J. L., The True Dates of the Chinese Maritime Expeditions in the Early Fifteenth Century, in T'oung Pao 34/5, Second Series (1939), 341-413.

Eisenstein, H., Zu drei nordeuropäischen Tieren aus Ibn Sa'id's Geographie, in Acta orientalia 54 (1993), 53-61.

Faroqhi, S., Exotic Animals at the Sultan's Court, in Another Mirror for Princes. The Public Image of the Ottoman Sultans and Its Reception, Istanbul 2008, 87-101.

Fauvelle-Aymar, F.-X., Le Rhinocéros d'or. Histoires du Moyen Âge africain, Paris 2013.

Giese, M., Die Tierhaltung am Hof Kaiser Friedrichs II. zwischen Tradition und Innovation, in K. Görich et J. Keupp (éd.), Herrschaftsräume, Herrschaftspraxis und Kommunikation zur Zeit Kaiser Friedrichs II., Munich 2008, 121-71.

Halm, H., Der nubische baqt, in U. Vermeulen et D. De Smet (éd.), Egypt and Syria in the Fatimid, Ayyubid and Mamluk Eras. II. Proceedings of the 4th and 5th International Colloquium organized at the Katholieke Universiteit Leuven in May 1995 and 1996 (OLA 83), Louvain 1998, 63-103.

Hamy, E. T., Document inédit pour servir à l'histoire de la ménagerie des Valois, in Bulletin du Muséum d'histoire naturelle, année 1905, 2, 68-70. [201]

Hauck, K., Tiergarten im Pfalzbereich, in Deutsche Königspfalzen, Beiträge zu ihrer historischen und archäologischen Erforschung Bd I, Göttingen 1963, 30-74.

Kantorowicz, E., CEuvres, Paris 2000.

König-Lein, S., Simile alla natura: die Darstellung exotischer Tiere in der Florentiner Malerei des Quattrocento, Weimar 1997.

Kruk, R., Zarafa: Encounters with the Giraffe, from Paris to the Medieval Islamic World, in B. Gruendler et M. Cooperson (éd.), Classical Arabic Humanities in Their Own Terms. Festschrift for Wolfahrt Heinrichs on his 65th Birthday, Leyde 2008, 568-92.

Laborde, L. de, Les Ducs de Bourgogne: études sur les lettres, les arts et l'industrie pendant le XV siècle, et plus particulièrement dans les Pays-Bas et le duché de Bourgogne, 3 vol., Paris 1849-1852.

Lagueux, O., Geoffroy's Giraffe: The Hagiography of a Charismatic Mammal, in Journal of the History of Biology 36/2 (2003), 225-47.

Le Glay, E., Histoire des comtes de Flandre, jusqu'à l'avènement de la Maison de Bourgogne. Tome premier, Bruxelles 1863 .

Lievois, D. et B. Van den Abeele, Une ménagerie princière entre Moyen Âge et Renaissance. La Cour des Lions à Gand de 1421 à 1641, in Reinardus 24 (2012), 77-107.

Liscomb, K., Foregrounding the Symbiosis of Power. A Rhetorical Strategy in Some Chinese Commemorative Art, in Art History 25/2 (2002), 135-61.

Loisel, G., Histoire des ménageries de l'Antiquité à nos jours, 3 vol. Paris 1912.

Løkkegaard, F., Bakt, in $E I^{2}$, i, 966.

Mas-Latrie, M.-L. de, Histoire de l'île de Chypre sous le règne des princes de la maison de Lusignan, 3 vol., Paris 1852-1861.

Meli, P., Firenze di fronte al mondo islamico. Documenti su due ambasciate (1487-1489), in Annali di Storia di Firenze 4 (2009), 243-73.

Mikhail, A., The Animal in Ottoman Egypt, Oxford 2014.

Morales Muñiz, D. C., La fauna éxotica en la Peninsula Ibérica: apuntes para el estudio del coleccionismo animal en el Medievo hispánico, in Espacio, tiempo y forma. Serie III, in Historia medieval 13 (2000), 233-70.

Muhanna, E. I., The Sultan's New Clothes: Ottoman Mamluk Gift Exchange in the Fifteenth Century, in Muqarnas 27 (2010), 189-207. 
Oleson, T. J., Polar Bears in the Middle Ages, Canadian Historical Review 31/1 (1950), 47-55.

Paravicini, W., Animaux pour un roi mourant. Louis XI et les Hanséates entre 1479 et 1483, in P. Contamine, T. Dufour, et B. Schnerb (éd.), Commerce, finances et société (XI-XVI siècle) Recueil de travaux d'histoire médiévale offert à M. le Professeur Henri Dubois, Paris 1993, 101-21.

Pastoureau, M., Les animaux célèbres, Paris, 2001.

Paviot, J., Le séjour de l'ambassade de Geoffroy de Langley à Trébizonde et à Constantinople en 1292, in Médiévales 12 (1987), 47-54. [202]

Potin, Y., Saint Louis l'Africain. Histoire d'une mémoire inversée, in Afrique et histoire (2003), 1, 23-74.

Reindl-Kiel, H., Dogs, Elephants, Lions, a Ram and a Rhino on Diplomatic Mission : Animals as Gifts to the Ottoman Court, in S. Faroqhi (éd.), Animals and People in the Ottoman Empire, Istanbul 2010, 271-85.

Ševčenko, N. P., Wild Animals in the Byzantine Park, in A. Littlewood, H. Maguire, et J. WolschkeBulmahn (éd.), Byzantine Garden culture, Washington 2002, 69-86.

Schnoor, F., Eine Sensation am Hof des Dogen von Venedig. Die Löwengeburt von 1316 im Spiegel lateinischer Gedichte, in Reinardus 22 (2010), 126-47.

Shehada, H. A., Mamluks and Animals: Veterinary Medicine in Medieval Islam, Leyde 2013.

Shehada, H. A., From the Far North to the Near East:Venice as an Intermediary in the Supply of Gyrfalcons to the Mamluks, in G. Christ et F.-J. Morche (éd.) Cultures of Empire: Rethinking Venetian Rule, 1400-1700: Essays in Honour of Benjamin Arbel, Leyde 2020, 369-82.

Spaulding, J., Mediaeval Christian Nubia and the Islamic World: A reconsideration of the Baqt Treaty, in The International Journal of African Historical Studies 28/3 (1995), 577-94.

Tinguely, F., L'écriture du Levant à la Renaissance : enquête sur les voyageurs français dans l'empire de Soliman le Magnifique, Genève 2000.

Vallet, É., Du système mercantile à l'ordre diplomatique : les ambassades entre Égypte mamlūke et Yémen rasūlide ( $\mathrm{VII}^{\mathrm{e}}-\mathrm{IX}^{\mathrm{e}} / \mathrm{XIII}^{\mathrm{e}}-\mathrm{VV}^{\mathrm{e}}$ siècle), in Les relations diplomatiques au Moyen Âge. Formes et enjeux. XLI congrès de la SHEMSP, Paris 2011, 269-301.

Vassilieva-Codognet, O., "Plus blans que flours de lis": Blanchart l'ours blanc de Renart le Nouvel, les ménageries royales et les encyclopédies du XIII ${ }^{\mathrm{e}}$ s., in Reinardus 27 (2015), 220-48. 